\title{
Value of skin testing children with a family history of food allergy before ingestion of suspect food allergens
}

\author{
Arunmozhi Dominic ${ }^{1 *}$, Vaishaali Manga ${ }^{1}$, Immaculate Nevis ${ }^{2}$, Laura Kim³ ${ }^{3}$, Harold Kim ${ }^{1,4}$ \\ From Canadian Society of Allergy and Clinical Immunology Annual Scientific Meeting 2014 \\ Ottawa, ON, Canada. 23-26 October 2014
}

\section{Background}

A family history of food allergy can cause anxiety in parents. This may prevent food introduction in their children. Current guidelines recommend skin testing only when there is a reaction to a food in that specific patient. When there is a family history of food allergy, parents frequently ask their physicians for food testing of their children prior to introduction of specific foods. We conducted this study to determine whether allergy skin testing reduces anxiety levels in parents thereby leading to food introduction.

\section{Methods}

The parents of 50 children with a family history of food allergy completed a Visual Analog Score (VAS) to estimate their anxiety to give their children the specific food of concern. Previously, the children had not eaten the food. The VAS scores were recorded pre- and post-skin testing on a scale from 0 to 10 . The likelihood of food introduction pre- and post-skin testing was estimated.

\section{Results}

The mean age of the children was 3.6 years; the majority were males (62\%). Approximately $58 \%$ of patients' parents, $38 \%$ siblings and $4 \%$ other relatives had food allergy. Most children (78\%) had family history of a single food allergen and $60 \%$ had a family history of allergy to peanuts. All children tested negative for the food allergen of concern. Mean VAS was statistically different pre- and post-skin testing (pre VAS mean $=7.83$ vs post VAS mean $=2.15 ; \mathrm{p}=<0.0001)$. The likelihood of food introduction pre- and post testing was $4 \%$ and $92 \%$ respectively.

'Division of Clinical Immunology and Allergy, Western University, London, Ontario, Canada

Full list of author information is available at the end of the article

\section{Conclusion}

Skin testing reduces the anxiety of parents of children with a family history of food allergy prior to introduction of the food allergen of concern. The food is more likely to be introduced into the diet after negative skin testing. Although it did not occur in this study, there is a still a risk of false positive skin testing.

\section{Authors' details}

${ }^{1}$ Division of Clinical Immunology and Allergy, Western University, London, Ontario, Canada. ${ }^{2}$ Department of Clinical Epidemiology and Biostatistics, McMaster University, Hamilton, Ontario, Canada. ${ }^{3}$ McGill University, Montreal, Quebec, Canada. ${ }^{4}$ Division of Clinical Immunology and Allergy, McMaster University, Hamilton, Ontario, Canada.

Published: 18 December 2014

doi:10.1186/1710-1492-10-S2-A29

Cite this article as: Dominic et al:: Value of skin testing children with a family history of food allergy before ingestion of suspect food allergens. Allergy, Asthma and Clinical Immunology 2014 10(Suppl 2):A29.

Submit your next manuscript to BioMed Central and take full advantage of:

- Convenient online submission

- Thorough peer review

- No space constraints or color figure charges

- Immediate publication on acceptance

- Inclusion in PubMed, CAS, Scopus and Google Scholar

- Research which is freely available for redistribution 